Vol. 8, Issue 12, December 2021

DOI: $10.17148 /$ IARJSET.2021.81217

\title{
EARTHQUAKE RESISTANT BUILDINGS: AN OVERVIEW
}

\author{
V.Santhana Lakshmi ${ }^{1}$, K.Latha ${ }^{2}$ \\ ${ }^{1}$ UG- Civil Engineering, Meenakshi Sundararajan Engineering College, Chennai, Tamilnadu \\ ${ }^{2}$ Assistant professor, Department of Commerce, SDNB Vaishnav College for women, Chennai, Tamilnadu
}

\begin{abstract}
Earthquakes are unexpected and uncontrolled catastrophic events. However it is dreaded all over the world, earthquakes are not the significant reason for injury or death at the point when they strike. It is generally expected the structures and the environment around them that put individuals in danger. The paper basically investigates on the factor that leads to the failure of structure during earthquake, base isolation and tuned mass damper technique which is used to make a building earthquake resistant and also highlight the materials used to build earthquake resistant buildings.
\end{abstract}

Keywords: Earthquake, Failure of structure, Resistant building.

\section{INTRODUCTION}

Earthquakes are the result of sudden movement along faults within the earth. The movement causes seismic waves, which propagate through the earth and cause the ground surface to shake. There are wide assortments of seismic tremor impacts - these might incorporate a gap opening up or down of many meters across a separation point. Consequently, it is beyond the realm of imagination to expect to design a quake proof building which is ensured to oppose every possible tremor. However, it is possible by applying earthquake engineering techniques which would increase the chances of survival of structures and occupants. Earthquake is a natural phenomenon, which can happen any time anyplace. Therefore, the buildings should be constructed in such a way that they are safe during such events. There are many techniques developed these days to make a building quake resistant.

As of now, there are many philosophies in earthquake engineering, utilizing trial results, virtual experiences and perceptions from past quakes to offer the necessary performance for the seismic danger at the site of interest. These range appropriately sizing the structure to be strong and ductile enough to endure the shaking with an acceptable damage. This paper brings out many arrangements, which can be executed in plan or construction of structures to make them quake safe.

\section{LITERATURE REVIEW}

The review of literature pertaining to 'Earthquake resistant buildings' are discussed with reference to the following theoretical study

DJ Dowrick (1977) The author explores the chief aspects of seismic risk evaluation and earthquake resistant design, various alternative design techniques, procedures to be adopted in earthquake regions.

DJ Dowrick (1988) The author has discussed advances in earthquake-resistant design. This study covers the entire design process, from aspects of loading to details of construction.

Pankaj Agrawal, Manish Shrikhande (2006) This book explains about earthquake resistant design of structures. The book talks about engineering seismology, structural dynamics, and seismic design parameters.

Jiro Takagi, Akira Wada (2019)This paper focused on seismic design philosophy and techniques for building and infrastructure. The design methodology covered in this paper will be effective in terms of protecting people; however it may not be sufficient for modern, complex societies.

Linlin Xie, Yang Cantian(2020)This paper investigates the performance of flexible pipes, metal flexible pipes (MFPs) and rubber flexible pipes (RFPs) with an expected deformation capacity of $400 \mathrm{~mm}$ was tested. The research outcome provides an important reference for the vulnerability research and seismic design of flexible pipes in seismically isolated buildings.

Vedant Mishra, Dr. M.P. Mishra(2020) This paper shows general concepts to be followed in earthquake resistant design. The study suggests that seismic tremor safe structure ought to have great seismic design with no design decision through building otherwise it will present intricacies in the building behavior. 
Cem Yenidogan (2021)This paper explores the fundamental principles of seismic isolation technology, impediments in extending the use of isolation systems, the current state of practice for the design and analysis. The study has overviewed the important perspective of earthquake protection devices.

\section{RESEARCH OBJECTIVES}

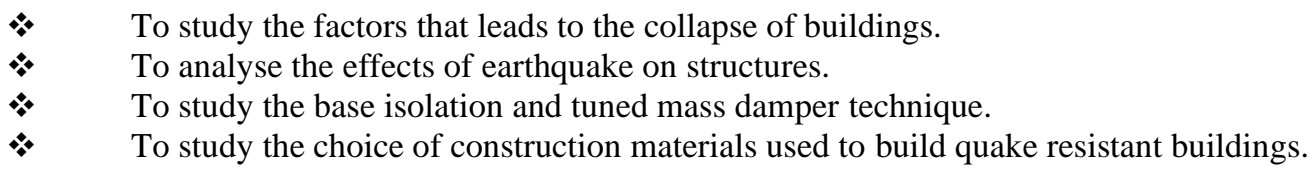

\section{SOURCES OF THE DATA}

The data is collected from various published and unpublished sources including journals, Magazines, Publications, Reports, Books, Periodicals, Articles, Research Papers, Websites, booklets.

\section{COLLAPSE OF BUILDINGS}

Tremors cause motion to the ground in irregular way. The horizontal vibration causes more damage. The reaction of a structure to an earthquake is a function of nature of the foundation soil; material, structure, size and method of construction; and the duration of ground movement. Because of parallel force made by tremor, entire design gets shake and high measure of stresses are developed in every component. The structure fails because of dislocation of reinforcement from structure and smashing of concrete when support gets out from the primary component.

The brutal ground movement pushes the structure quickly starting with one bearing then onto the next making it hard for the super-structure to constantly balance its heap because of inertial impacts. Result: while columns can twist, the swaying movement, when increased, snaps the structure and breakdowns. If the Earthquake lasts longer, the amplitude of vibration is more, for so the structure will deflect more and gets damaged. A superstructure can be harmed, not just because of the shaking which results from tremors yet in addition because of chain impacts like fire, land slide and so forth brought about by quake.

\section{EFFECTS OF EARTHQUAKE ON STRUCTURES}

\subsection{Inertia Forces in Structures}

The generation of inertia forces in a structure is one of the seismic influences that affect the structure. At the point when a quake causes ground shaking, the base of the building would move but the roof would be at rest. Since the walls and columns are attached to it, the roof is dragged with the base of the building. The tendency of the rooftop structure to remain at its original position is known as inertia. The inertia forces can cause shearing of the structure which can focus stresses on the weak walls in the structure resulting in failure or total collapse. More mass means higher inertia force that is the reason why lighter buildings sustain the earthquake shaking better.

\subsection{Horizontal and Vertical Shaking}

Seismic tremor causes shaking of the ground in all the three directions X, Y and Z, and the ground shakes arbitrarily to and fro along each of these axis directions. Usually, structures are intended to withstand vertical burdens, so the upward shaking because of seismic tremors (either adds or takes away vertical burdens) is handled through wellbeing factors utilized in the plan to help vertical burdens. Horizontal shaking along $\mathrm{X}$ and $\mathrm{Y}$ directions is critical for the structures since it produces inertial force and lateral displacement and subsequently load transfer way will be given to prevent its detrimental influences on the structure.

Appropriate inertia force transfer path can be made through satisfactory plan of floor piece, walls or sections, and connections between these primary components. It is worth mentioning that the walls and columns are important members in transferring the inertial forces. It is shown that, masonry walls and thin reinforce concrete columns would create weak points in the inertia force transfer path.

\subsection{Deformations in Structures}

At the point when a structure encounters seismic tremor and ground shaking happens, the base of the structure moves with the ground shaking. The rooftop would not be same as that of the foundation of the building. This distinction in the movement makes inertia forces in sections which tend to return the segment to its original position. These internal forces are called stiffness forces. The stiffness forces would be higher as the size of segments gets higher. The stiffness power in a segment is the section solidness times the overall displacement between its ends.

\section{A STUDY ON BASE ISOLATION AND TUNED MASS DAMPER TECHNIQUE}




\title{
International Advanced Research Journal in Science, Engineering and Technology
}

\author{
Vol. 8, Issue 12, December 2021
}

DOI: $10.17148 /$ IARJSET.2021.81217

\subsection{Base Isolation}

Base isolation is generally utilized in the seismic tremor safe plan. This passive control procedure essentially decouples the design starting from the earliest stage by presenting an adaptable or sliding sort interface. During the quake, when the recurrence of the ground movement is near the normal recurrence of the structure, the design can influence essentially. Base isolation redirects and dissipates the seismic energy, bringing down the normal recurrence of the construction. That way, the base isolation limits the displacement of the structure.

\subsubsection{Principle of Base Isolation}

The essential rule behind base isolation is that the reaction of the design or a structure is changed to such an extent that the ground underneath is equipped for moving without transmitting minimal or no movement to the structure above. A total separation is possible just in an optimal framework. In a genuine situation, it is important to have a vertical support to move the vertical loads to the base.

\subsubsection{Base Isolation System}

The fundamental element of the base isolation innovation is that it brings flexibility into the association between the structure and the foundation. In addition to permitting movement, the isolators are regularly intended to assimilate energy and in this manner add damping to the framework. This helps in additional lessening the seismic reaction of the structure. A large number of the base isolators look like enormous elastic cushions, in spite of the fact that there are different sorts that depend on sliding of one part of the structure comparative with other. It ought to be noticed that base isolation isn't reasonable for all structures. Tall elevated structures or structures on exceptionally delicate soil are not appropriate for base isolation. Base isolation is best for low to medium ascent structures which are found on hard soil.

\subsection{Tuned Mass Damper}

The seismic waves brought about by a quake will make structures sway and oscillate in different ways relying upon the frequency and direction of ground movement, and the height and design of the structure. Seismic movement can cause oscillations of the structure which might lead to collapse of structure. To improve the structure's seismic exhibition, a legitimate structure configuration is performed connecting with different seismic vibration control advancements.

Tuned Mass Damper (TMD), also known as a harmonic absorber or seismic damper, is a device mounted in buildings to decrease mechanical vibrations, comprising of a mass mounted on at least one damped springs. A tuned mass damper (TMD) is a vibrating mass that moves out of phase with the movement of the building it is suspended to. With its out of phase movement, the inertial force of the TMD mass subsides the full vibration of the building by dispersing its energy.

\subsubsection{Working Of Tuned Mass Damper}

A tuned mass damper (TMD) comprises of a mass (m), a spring (k), and a damping device (c), which disseminates the energy made by the movement of the mass (generally in the form of heat). From the laws of physics, we know that $\mathrm{F}=$ ma. This implies that when an external force is applied to a system, for example wind pushing on a skyscraper, there must to be acceleration.

Subsequently, individuals in the high rise would feel this speed increase. To cause the tenants of the building to feel more good, tuned mass dampers are put in structures where the horizontal deflections from the wind's force are felt the greatest, successfully making the structure stand moderately still. At the point when the structure starts to sway, it sets the TMD into movement through the spring and, when the structure is constrained right, the TMD at the same time forces it to the left. Preferably, the frequencies and amplitudes of the TMD and the structure ought to almost coordinate so that each time the wind pushes the structure; the TMD makes an equivalent and inverse push on the structure, keeping its horizontal displacement at or close to nothing.

If their frequencies were essentially unique, the TMD would make pushes that were out of sync with the pushes from the wind, and the structure's movement would be uncomfortable for the tenants. If their amplitudes were altogether unique, the TMD would, for instance, make pushes that were in a state of harmony with the pushes from the wind yet not exactly a similar size and the structure would in any case encounter an excess of movement. The effectiveness of a TMD depends on the mass proportion (of the TMD to the actual design), the proportion of the frequency of the TMD to the frequency of the building, and the damping proportion of the TMD. Wide span structures just as slender tall designs will quite tend to be excited to high vibration amplitudes in one of their essential mode shapes, for instance by wind or walking and bouncing individuals. Low natural frequencies are typical for this type of structure, because of their aspects, similar to their low damping. With GERB Tuned Mass Dampers (TMD), these vibrations can be reduced effectively.

\section{CHOICE OF CONSTRUCTION MATERIALS}




\title{
International Advanced Research Journal in Science, Engineering and Technology
}

\author{
Vol. 8, Issue 12, December 2021
}

DOI: $10.17148 /$ IARJSET.2021.81217

\subsection{Reinforced Concrete}

Construction material is crucial for the tremor resistance and durability of structure. The safest structure will be the one made of all steel, as it is an amazingly impressive material. Reinforced Concrete is another reasonable material for quake safe development of structures. It is a good, solid, durable and economical material used in construction; however the condition is that the nature of construction ought to be acceptable. It was seen during the later seismic tremor, that most structures made with concrete, stayed remaining without experiencing a lot of harm.

\subsection{Other Materials}

A brick, stone or mud house breaks even with moderate quakes. But, these materials can be effective when fortified with RCC components at major points. Masonry structures become brittle when enormous deflections occur, so RCC groups can reinforce them at customary spans. A wooden frame building is great as it ingests shock uniformly and vibrates along the shake and improbable to implode. The risk with wooden frame structures is that it is profoundly inflammable and has restricted use.

\subsection{Innovative Materials}

Researchers and designers are growing new structure materials with much more prominent shape maintenance. Innovations like shape memory amalgams can both bear substantial strain and return to their original shape, while fiber-reinforced plastic wrap made by an assortment of polymers can be wrapped over columns and give up to $38 \%$ more prominent strength and flexibility.

Engineers are additionally going to natural elements. The rigid fibers of mussels and the solidarity to-measure proportion of arachnid silk have promising abilities in making structures. Bamboo and 3D printed materials can also work as lightweight, interlocking constructions with boundless structures that might possibly give significantly more prominent protection from structures. Over years, engineers and researchers have formulated strategies to make some compelling seismic tremor confirmation structures. But these modern innovations and materials cannot completely withstand a powerful earthquake unscathed.

Throughout the long term, engineers and researchers have formulated strategies to make some compelling seismic tremor confirmation structures. As cutting edge the innovation and materials are today, it isn't yet workable for working to totally withstand an amazing quake solid. Still, if a structure can permit its inhabitants to escape without collapsing and saves lives and networks, we can think about that as an extraordinary achievement.

\section{CONCLUSION}

The goal of the paper was to study the reason for collapse of buildings during earthquake, to analyze the effects of seismic tremor and most importantly to study base isolation and tuned mass damper technique and also to highlight the choice of materials for constructing quake resistant buildings. It can be concluded that by using these modern technologies and innovative materials engineers cannot build $100 \%$ quake resistant buildings, still impact due to earthquake on buildings can be reduced to a great extent.

\section{REFERENCES}

1. Cem Yenidogan (2021) "Earthquake-Resilient Design of Seismically Isolated Buildings: A Review of Technology", Vibration, 2021 https://www.mdpi.com/2571-631X/4/3/35

2. DJ Dowrick (1977) “Earthquake Resistant Design- A Manual for Engineers and Architects”,https://trid.trb.org/view/72470

3. DJ Dowrick (1988) "Earthquake resistant design", https://www.osti.gov/biblio/7154842

4. Jiro Takagi, Akira Wada (2019) "Recent earthquakes and the need for a new philosophy for earthquake-resistant design", Elsevier https://www.sciencedirect.com/science/article/pii/S026772611730876X

5. Linlin Xie, Yang Cantian (2020) "Experimental investigation of the seismic performance of flexible pipes for seismically isolated buildings", Elsevier https://www.sciencedirect.com/science/article/abs/pii/S0141029620309299

6. Pankaj Agrawal, Manish Shrikhande (2006) "Earthquake Resistant Design of Structures", books.google.com

7. Vedant Mishra, Dr. M.P. Mishra(2020) "General Concepts to be Followed in Earthquake Resistant Design as a Safety Measures for Economic Construction", academia.edu 